\title{
EL TRIBUNAL DE LA SANTA INQUISICIÓN SE REUNÍA EN ALCANTARILLA
}

\section{THE INQUISITION TRIBUNAL MET IN ALCANTARILLA}

José Riquelme: Asociación de Víctimas de Talidomida y otras Inhabilidades de España.

jose.riquelme@ozu.es

\section{CURRÍCULUM VITAE}

Presidente de la Asociación de Víctimas de Talidomida y otras Inhabilidades de España (AVITE). Destaca por su labor de lucha por el reconocimiento de los afectados por dicha droga a nivel nacional e internacional.

\section{RESUMEN}

El Tribunal de la Santa Inquisición se reunía en la localidad murciana de Alcantarilla, en la Casa del Santo Oficio. Un caserón que fue rehabilitado y ahora es la Biblioteca Pública Municipal. Pero aún conserva muchos elementos de lo que fue aquel edificio, como las ventanas que daban a la mazmorra, ahora convertida en sala de reuniones. Todo lo que fuera en contra del Cristianismo se juzgaba en este lugar, entre otros en toda España. Por ejemplo se llevaban a cabo procesos contra los pecados de la sexualidad, como la bigamia, la fornicación y la homosexualidad.

\section{PALABRAS CLAVE}

Inquisición - Pecados - Bigamia - Homosexualidad 


\section{ABSTRACT}

The Inquisition Tribunal met in the Murcian town of Alcantarilla, in the House of the Holy Office. A mansion that was renovated and it is now the Public Library. But still retains many elements of what it was that building such as windows that overlooked the pit, now a meeting room. All that was against Christianity was judged in this place, among others in Spain. For example processes were carried out against the sins of sexuality, such as bigamy, fornication and homosexuality.

\section{KEY WORDS}

Inquisition - Sins - Bigamy - Homosexuality

\section{ÍNDICE}

1. Introducción

2. Procesos por los pecados de la sexualidad

\subsection{Bígamos}

2.2 Fornicarios

2.3 Homosexuales

\section{TEXTO:}

\section{Introducción}

El Tribunal de la Santa Inquisición se reunía en Alcantarilla (Murcia) en la Casa del Santo Oficio, Casa de las Cayitas o Casa de la Inquisición -tiene tres denominaciones 
en la actualidad-, muestra de la arquitectura de los s. XVII y XVIII. Era uno de los tribunales inquisidores que existían en España.

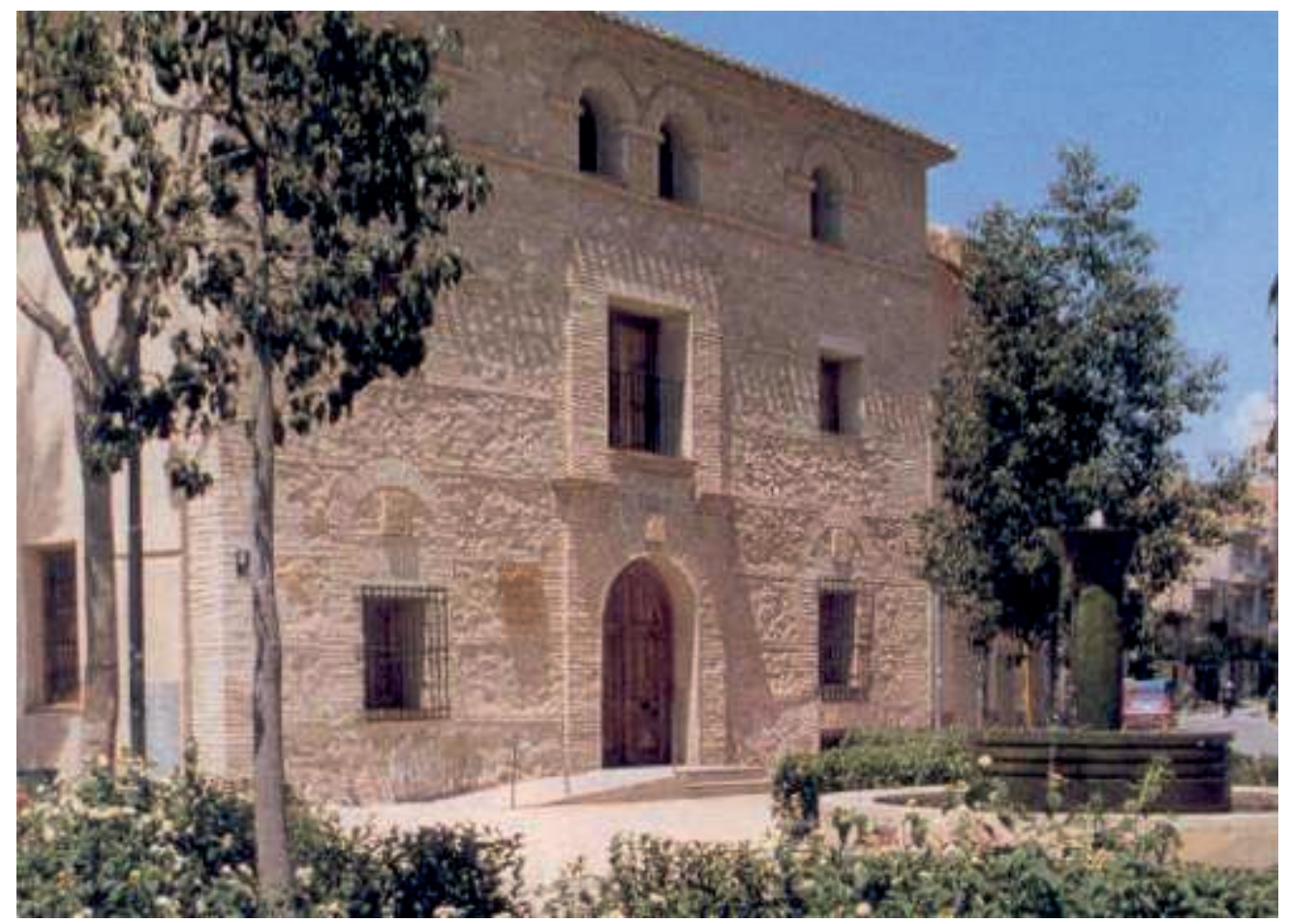

La Casa de las Cayitas

Aquí se congregaban para celebrar los juicios sumarísimos de la España inquisitorial a prostitutas, homosexuales, brujas... por eso a la localidad de Alcantarilla, se la conoce con el sobrenombre de "pueblo de las brujas", ya que, por aquella época, abundaban en esta plaza. 


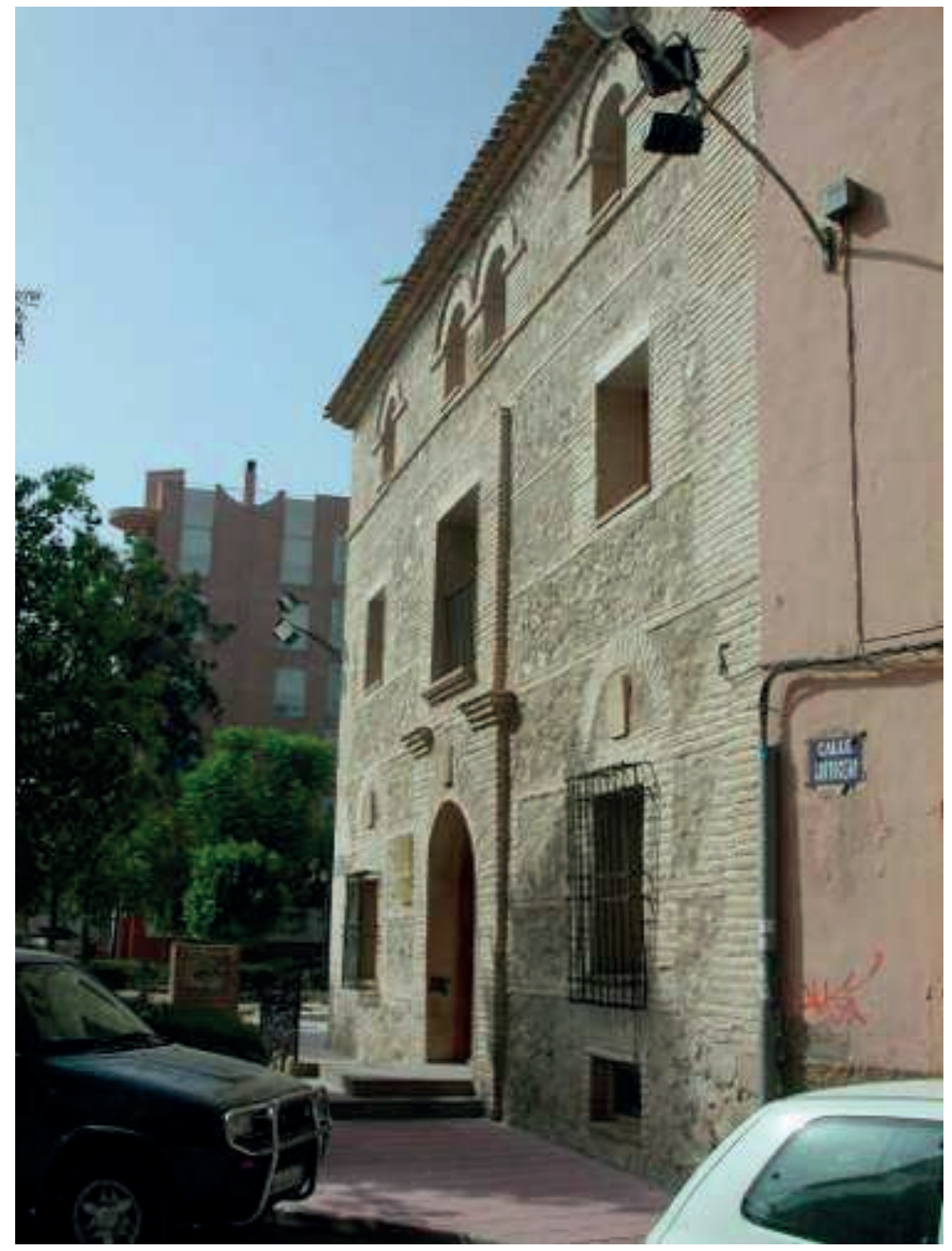



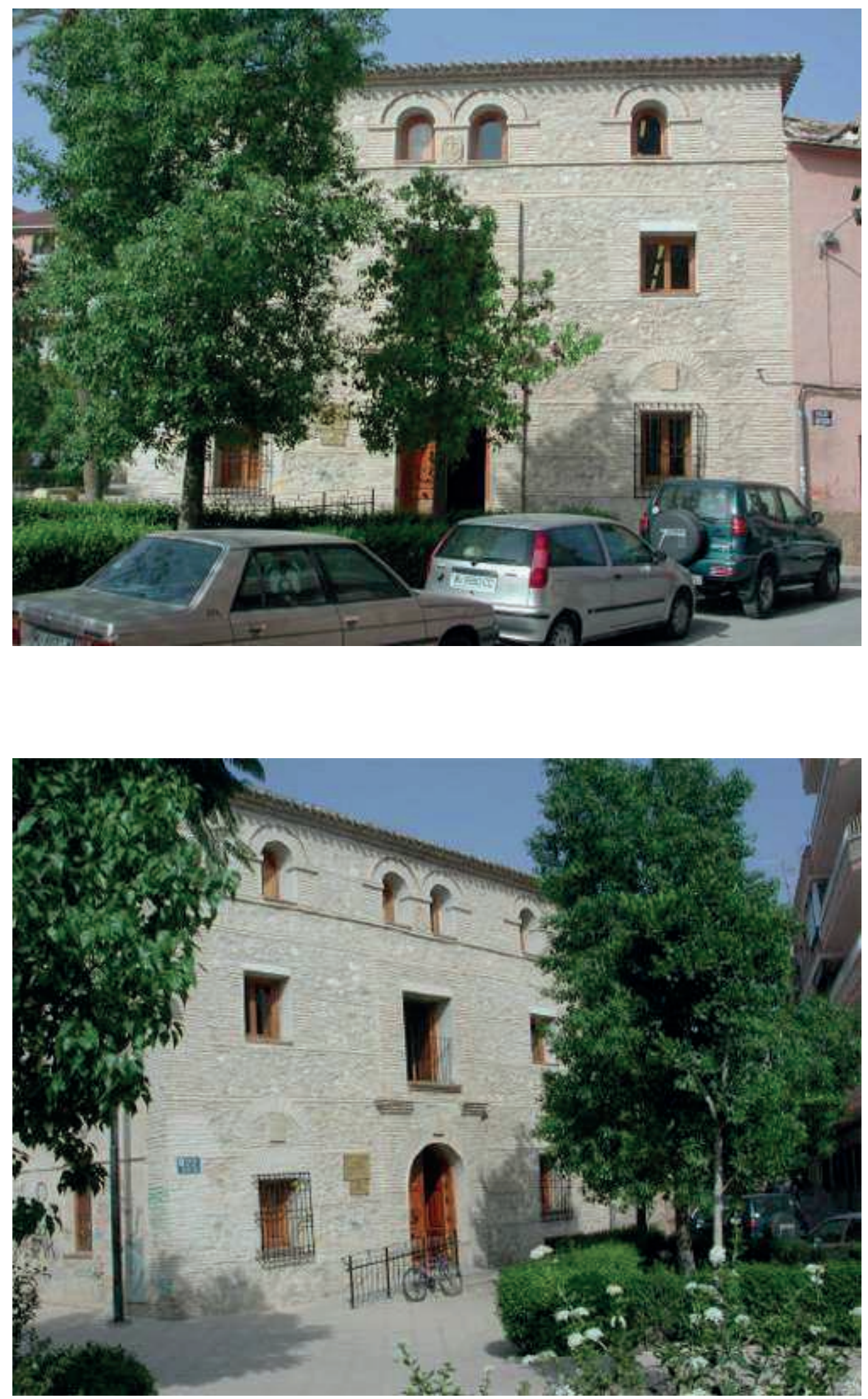

Otras perspectivas de la Casa de las Cayitas 
En dicha casa, o caserón, ahora rehabilitado y convertido en Biblioteca Pública Municipal, aún se conservan las mazmorras donde se encerraba a los condenados, a la espera de la celebración del juicio sumarísimo, para posteriormente trasladarlos, en carros, hasta Toledo, a fin de ejecutarlos en la hoguera o al garrote vil.

Las mazmorras están en el subsuelo y sus ventanitas a la altura de los ojos a ras del suelo. Resulta estremecedor, asomarse desde adentro hacia afuera.

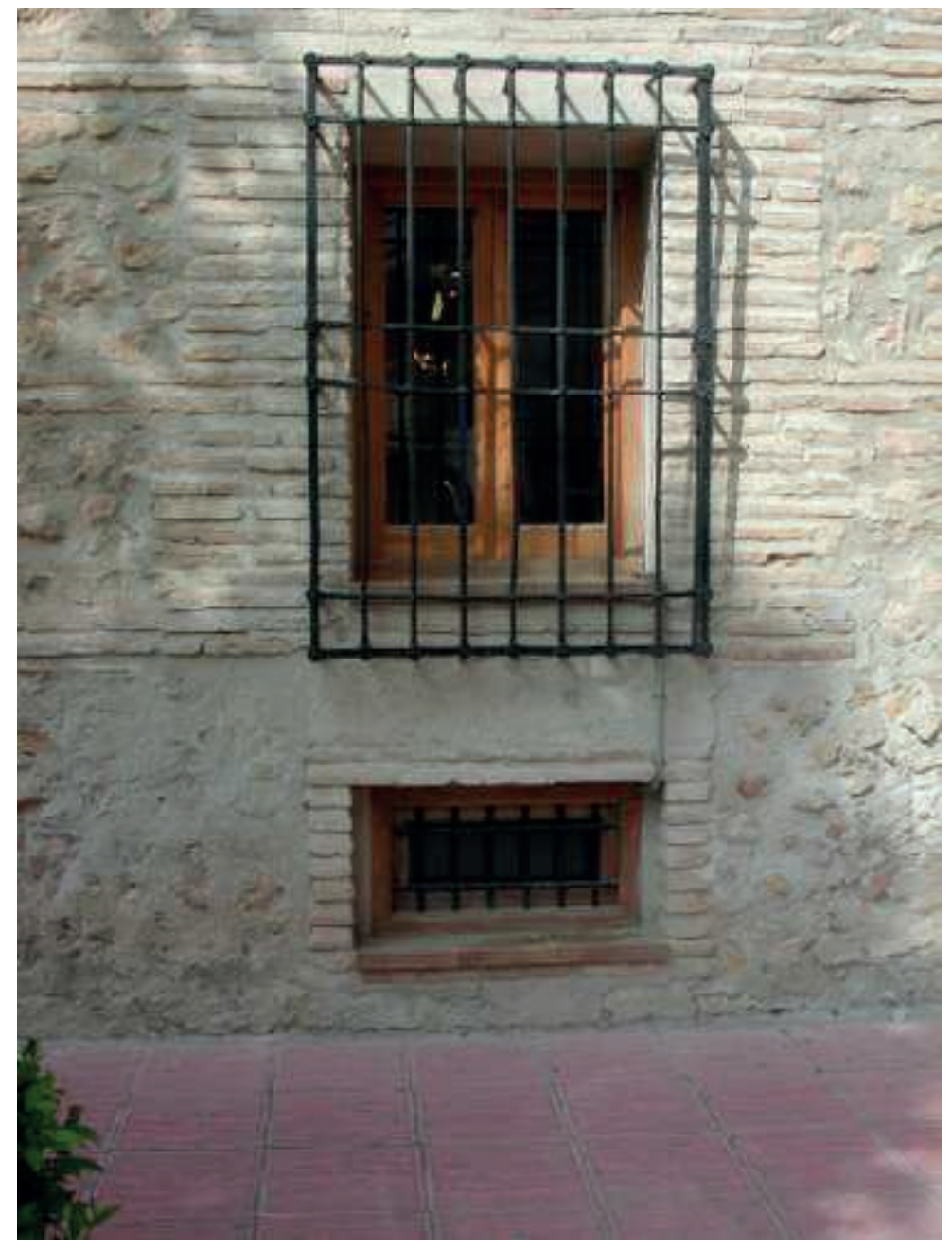

La ventana inferior corresponde a una de las mazmorras 


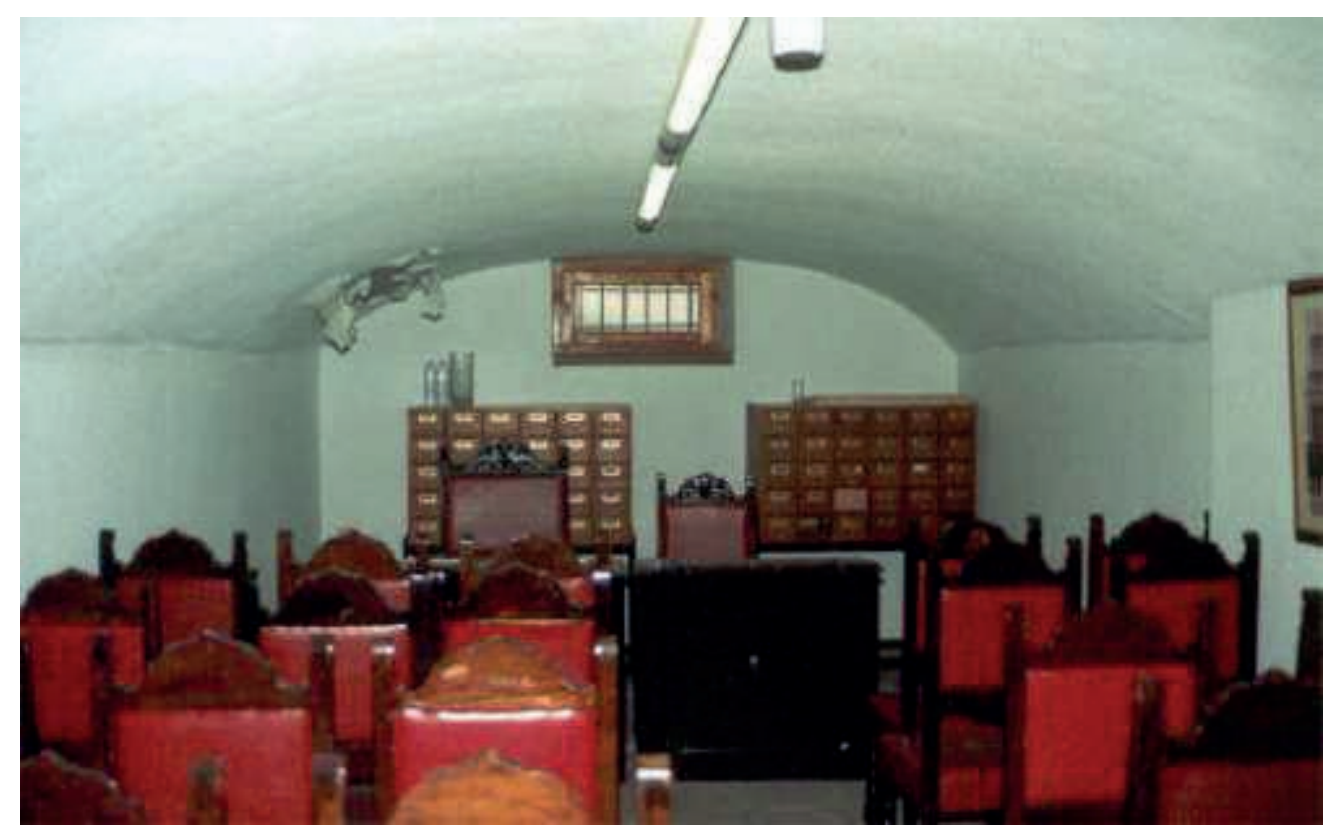

La mazmorra rehabilitada y convertida en sala de reuniones

En el siglo XVIII, según Gonzalo Anes, "la Cédula de 13 de febrero de 1.745 es motivada por la noticia llegada al Consejo de Castilla, de que los inquisidores de la ciudad de Murcia, habían entablado una disputa con el Obispo, con motivo de que el comisario y familiares de la Inquisición de la villa de Alcantarilla habían pretendido, en la iglesia parroquial de San Pedro Apóstol, un banquillo privativo y en lugar preeminente a los demás vecinos, la disputa la habían resuelto los mismos inquisidores, y había impuesto censuras y otras penas. Ante tal abuso el rey negó la pretendida preeminencia de asiento y previno al Consejo de la Inquisición que sus ministros delegados en los tribunales de fuera procediesen en lo sucesivo con la debida moderación, absteniéndose de dar principio a semejantes litigios con censuras, prisiones y multas".

El Santo Tribunal fue suprimido durante el reinado de Fernando VII en el siglo XIX $\mathrm{y}$, como referencia de la existencia de este tribunal de la sangre, se encuentra una inscripción en el pie de una pila de mármol de la parroquia de San Pedro Apóstol en la que se advierte la presencia de D. Ginés de Saavedra Pacheco, Comisario del Santo 
Oficio de la Inquisición, quien diera por su devoción esta pila de agua. La inscripción dice así: "el doctor D. Ginés de Saavedra y Pacheco, comisario del Santo Oficio de la Inquisición, Capellán Mayor de las galeras de España dio por sus devociones esta pila de agua bendita a esta parroquia de la villa de Alcantarilla. Génova año 1.723."

El Tribunal del Santo Oficio de la Inquisición fue instituido en España por bula del Papa Sixto IV, el 1 de noviembre de 1478, a petición de los Reyes Católicos, como medio para combatir el peligro de los judeoconversos que hacían peligrar su política de unidad religiosa, al margen de otras posibles motivaciones socioeconómicas.

Cierto es que el gran número de estos judeoconversos había concentrado en sus manos un gran poder, tanto intelectual como económico y político, y eran mirados con recelo, cuando no con auténtico odio o envidia, tanto por las clases elevadas, como por los más humildes plebeyos.

Era el vocabulario utilizado en aquella época y, entre otras, eran comunes las siguientes palabras: hacienda inquisitorial, confiscaciones, canonjías, varas de alguaciles, juros, inquisidores, fiscales, notarios, masonería, sacrilegios, clero pecador, irreverencias, blasfemias, etc.

\section{Procesos por los pecados de la sexualidad}

\subsection{Bígamos}

La monogamia es característica del cristianismo y el matrimonio indisoluble. En las Cortes de Segovia de 1532, fue solicitado que la infracción se considerase como delito capital, lo que fue rehusado, aunque se concedió la confiscación de la mitad de los bienes del reo. En 1584 las Cortes de Valladolid sustituyeron la pena de galeras por la de 10 años de destierro. 
También es probable que los inquisidores vieran en este delito connotaciones con la poligamia musulmana, lo que hizo que en sus primeros momentos fueran muy duros con los bígamos.

A partir de 1573, y por ordenes de la Suprema, cuando los tribunales moderaron su rigor, no pudiendo ser detenidos los bígamos, más que en el caso de que se probase totalmente su primer matrimonio, el número de acusados desciende en casi todos los Tribunales y a mediados del siglo XVIII casi no existen.

La mayoría de los procesados solían ser hombres, siendo casos muy raros las mujeres. Sin embargo, cuando éstas se saltaban de mala manera el sacramento del matrimonio lo hacían a conciencia, como es el caso de Ana Yáñez, que se casó nada menos que 4 veces y, cuando se cansó de una vida tan rutinaria, se marchó a Orán, a vivir con los soldados allí acuartelados. Lo curioso es que, cuando decidió disfrutar plenamente de la vida, tenía ya 60 años. Su edad no la impidió recibir 100 azotes y ser condenada a 3 años de reclusión.

Cuando son detenidos, los bígamos recurren a todo tipo de explicaciones para justificar su acción y librarse del castigo, que nunca era leve.

Vemos a Francisco Box, de Alguazas (Murcia), el cual, a los 16 años, se casó por vez primera. Habiéndose cansado de su mujer, tomó segunda esposa. Sin embargo, alega que las dos veces lo hizo "por ser simple y de poco entendimiento, atontado y alocado". Sus pocas luces le hicieron recibir 100 azotes y servir 3 años en galeras.

Otro es el caso de Luis Ballesteros, de Pliego (Murcia). Se casó primeramente en Santiesteban, donde dejó a su mujer y vino a Pliego. Aquí, "una morisca se echó a sus pies y le dijo que por amor de Dios, la remediase casándose con ella, porque era cristiana y excusaría de que se fuese a manos de enemigos y él, con celo de que aquel 
alma no se perdiese, se casó con ella..." Los inquisidores no vieron muy claro ese celo salvador de almas y le condenaron nada menos que a 300 azotes y a 10 años de destierro.

Había quienes se tomaban el asunto a la tremenda, como el berberisco Martín Soler, que se casó 3 veces. A su primera mujer, Isabel Ballester, la asesinó. A la segunda, María Dato, "la Bermeja", la puso pleito de divorcio y lo consiguió, volviéndose a casar. Al parecer el asunto del divorcio no estaba claro y tampoco se le pudo probar el asesinato, por lo que la causa se archivó.

El cochero murciano Diego de Avilés Cañizares tenía especial debilidad por las esclavas y se casó con 3 de ellas, exhibiendo falsas certificaciones, lo que le valió 200 azotes y destierro.

A veces, la bigamia era forzada, como le ocurrió a Pedro Gutiérrez Jafur, que estaba casado en Málaga. En Murcia conoció a otra mujer y tuvo relaciones con ella; el hermano de la moza, al enterarse, le dijo que eligiese entre la boda o el cementerio y, claro, eligió la boda, lo que le valió 200 azotes y 10 años de destierro.

Un caso muy curioso es el de Juan Navarro, vecino de Lorca. Este hombre se casó con Catalina Pérez, aunque al poco tiempo se enamoró de su cuñada, Juana Pérez, con la que tuvo amoríos. Su esposa Catalina, benévola y comprensiva, le consintió en casarse con su hermana. Sin embargo, Juan tenía un corazón volcánico, se enamoró de su otra cuñada, Luisa, y, con permiso de sus dos esposas anteriores, se casó con la hermana que le faltaba en su colección. Su suegro, Juan Pérez, era consentidor de la situación. Lo más curioso del caso es que era ya un hombre anciano cuando fue procesado (tenía más de 70 años) y, además, ciego. La Inquisición le condenó con 400 azotes y no le echó en galeras en consideración a su edad y estado físico. Las esposas- 
hermanas recibieron entre 400 azotes la primera y 200 las restantes. El suegro fue sacado a la pública vergüenza.

A modo de paréntesis, diremos que los gustos en cuestión de amores, entonces como ahora, eran variados. Muy poco agraciada era, en verdad, Josefa Eugenia Alominos, "muy pequeña, ojos pardos, cejas bastante pobladas, pelo castaño, muy picada de viruelas", todo lo cual no fue óbice para que se casara varias veces.

Debido, probablemente, a que tenían otros medios para solucionar sus problemas matrimoniales, son muy pocos los procesos de bígamos de categoría social superior. En Murcia se conocen sólo dos casos. Uno es el de Pedro de Ceballos, oficial de la Secretaría de Italia (Nápoles), que tan sólo fue condenado a 4 años de destierro. El otro corresponde a José Luis de Guzmán, Caballero de la Orden de Santiago, militar destinado en Cartagena. Como era íntimo amigo del gobernador, los inquisidores no se atrevían a prenderle en esa plaza y con engaños le atrajeron a Murcia, donde fue detenido y procesado, aunque con mucho miramiento.

Son 254 los procesos incoados por este delito por el Tribunal de Murcia, de los que tan sólo 49 corresponden a mujeres. Es de advertir que al contrario de otros Tribunales el número de causas no sólo no desciende durante el siglo XVIII, sino que, por el contrario, aumenta, ya que de 83 en el siglo XVII pasan a 99 en esa centuria.

\subsection{Fornicarios}

Son muchas las personas procesadas por la simple fornicación, aunque, por definición, ésta no puede, en modo alguno, ser considerada como un pecado. En realidad, el perseguir este tipo de delito consistió en una arbitrariedad de la Inquisición, quizá por confundirlo con lo que para ella era algo típicamente musulmán. 
Fue a partir de mediados del siglo XVI cuando se empezó a atacar duramente a quienes profesaban estas prácticas, siendo el proceso más antiguo el celebrado en Sevilla en 1559. Ese mismo año salieron en auto de fe doce reos.

Desde el primer momento, a este "pecado" se le añadió la sospecha de herejía. Así, en 1561, la Suprema indica que un tal Pedro Cestero, penitenciado por ello, debía ser, asimismo, procesado por hereje y por aquí se coló el delito de herejía. Inmediatamente comienzan a ser procesadas personas de acuerdo con este condicionante. De todas formas, que su extinción era prácticamente imposible es reconocido por la propia Suprema cuando, el 23 de noviembre de 1573, indica que los casos son muchos en todos los Tribunales y que, hasta el momento, se han conseguido muy pocos progresos.

Los primeros procesos por este delito en la Inquisición murciana, corresponden a 1562, y son varios: Diego de Buendía, vecino de Ojós; Juan Fernández, de Murcia; Catalina de Medina, de Hellín, y Juan Nofre, sin localidad conocida.

Todos los hechos de este tipo conducen a lo mismo: una defensa de la sexualidad libre y, sobre todo, de la prostitución.

Tenemos un claro exponente en el escribano Diego de León, quien afirmaba, sin tapujos, que el Concilio de Trento se realizó en dicha ciudad para que hubiese más putas. Por esto, y por otras aseveraciones como que "quien no presumía de honra no se podía salvar" o que "la Inquisición quemaba sin culpa y con testigos falsos", fue desterrado por 10 años.

Había quienes estas prácticas las llevaban al límite, como el matrimonio formado por Francisco Padilla y María de Sandoval, vecinos de Caravaca. A su hija la pusieron una cama en el coro de la ermita de San Sebastián y allí, con el beneplácito de sus 
progenitores, la moza se refocilaba con los lugareños, pues, al parecer, hacer el amor en lugar sagrado no era pecado.

Un clérigo de Moratalla, cuyo nombre está roto en el documento, que era de generación de conversos, no se recataba en afirmar que los parientes debían tener acceso carnal entre sí, ya que Adán casó a sus hijas con sus hijos. Persuadió a varios feligreses a cometer incesto, con el escándalo consiguiente. Sin embargo, y esto es curioso, en un rápido proceso, la Inquisición tan sólo le condenó a 6 meses de cárcel.

Algo relacionado con esto es lo que decía el agricultor de la huerta murciana Diego Piñuela, ya que, según él, "a mi madre se lo puedo yo hacer y no es pecado".

Una curiosa teoría, en la que se mezclan la religión y la profilaxis, es la sustentada por el morisco Diego Hernández Vegil, quien afirmaba que dos hermanos podían tener acceso carnal sin pecar con la misma mujer, pues "en orinando la mujer, podía entrar el otro". No hubo forma de hacerle reconocer su error.

Relacionada, quizá, con esta teoría es la de Catalina Medina, vecina de Yecla, la cual tenía acceso carnal con nada menos que 4 hermanos simultáneamente, sin que para ella eso fuera el más mínimo pecado. Eran hermanos y, por tanto, como si fuese uno solo. Fue desterrada, pero Catalina quebrantó el destierro, deseosa de volver a estar junto a sus hombres. En 1564, fue nuevamente juzgada y esta vez la condena fue más dura: 200 azotes y 2 años de reclusión.

Otro caso es el de Juan Fernández, portugués avecindado en Cartagena en 1632. Era un pobre hombre que se dedicaba a pedir limosna y a solicitar, con mejores o peores modales, a cuantas mujeres se cruzaban en su camino. Afirmaba, y estaba plenamente convencido, de que todas las hembras eran suyas, puesto que él era Cristo, redentor del mundo. Al ser detenido se ratifica en sus opiniones y, es más, 
desafiando a los inquisidores, les promete que el próximo domingo, abriría las puertas de las cárceles y todos los presos saldrían libres. Los sesudos funcionarios inquisitoriales no saben si calificarle de pícaro, de loco, de mesianismo o judaísmo y acaban dejando la causa en suspenso.

Otros no eran tan escrupulosos, y con tal de que fueran mujeres quienes compartieran sus buenos ratos les daba igual. En realidad, la inmensa mayoría de los procesados opinaban simplemente que hacer el amor con una mujer, siempre que ella consintiera y pagándoselo, no podía ser considerado pecado, lo dijese quien lo dijese, ya que, como decía el labrador murciano Francisco Manresa, "los hombres tienen que irse con mujeres, no con burras". Asimismo, es frecuente la idea de que si el hombre no está bien con su mujer, como no puede separarse de ella, al menos le es lícito irse a pasar el rato con otra.

\subsection{Homosexuales}

Al otro extremo de la fornicación heterosexual se encuentra la homosexualidad, que, sin embargo, suele ser bastante rara en aquella época. En gran parte de la legislación secular era castigada con la hoguera. Sin embargo, en 1179, el Concilio de Letrán prescribió contra los clérigos reclusión en un convento de degradación. Por estas mismas fechas, los sodomitas eran castigados en España con lapidación y castración, pero los Reyes Católicos volvieron a encender las hogueras para ellos.

Al menos desde principio del siglo XVI, la Inquisición entendió de este delito, pues la de Sevilla, en 1506, procesó a varias personas y, al parecer, nada menos que 12 fueron quemadas. En un Breve de Clemente VII, de 24 de febrero de 1524, se ordena que estas causas sólo pueden ser conocidas por los Tribunales de Aragón, Cataluña y Valencia. 
Al parecer, en la jurisdicción de este último Tribunal, los sodomitas eran bastante abundantes, aunque sería preciso conocer si todos los procesados eran vecinos de allí o bien su abundancia es debida a que allí se juzgaban las causas de otros tribunales, que quizá sea lo más correcto.

No fue este, en modo alguno, un problema en Murcia y, por otra parte, las causas eran remitidas al Tribunal de Valencia, según ordena la Suprema, en fecha 13 de mayo de 1586. A mediados del siglo XVIII, la Inquisición murciana pretende hacerse cargo de estos casos, ya que alega que se están acrecentando. La respuesta de la Suprema es terminante: será Valencia quien, como hasta ese momento, los juzgue.

De todas formas, y a pesar de lo que decían los inquisidores murcianos, son muy pocos los casos conocidos. Tan sólo algunos religiosos solicitantes, como el de Josefa de las Heras. Esta mujer pasó su infancia en el colegio de Niñas Huerfanas de María y se casó a los 17 años. Continuó trabajando en esta institución y se relacionaba con las chiquillas allí recogidas hasta las últimas consecuencias, diciéndoles que eso no era pecado y que no tenían necesidad de confesarlo; las enseñó a desnudarse en el coro, mientras que el sacerdote decía misa, haciendo que todas se relacionasen en esos momentos entre sí. Era condición muy importante que no se lavasen las manos una vez hubiesen acabado sus "diversiones" y así habían de palpar el pan que luego comían. Al ser denunciada, en su proceso, Josefa declaraba que ella no hace sino enseñar lo que a ella la habían enseñado otras, con lo que descubre que la moral en dicho colegio no estaba muy atendida por quienes era su deber.

En definitiva, vemos que de los 117 procesos habidos por este delito, 100 son hombres y 17 mujeres, lo que indica que casi todos los procesados eran varones, siendo un caso raro entre mujeres, como ocurre en casi todos los demás tribunales. 